\title{
Sensitivity of a Vacuum Aspiratory Culture Technique for Diagnosis of Localized Cutaneous Leishmaniasis in an Endemic Area of Leishmania (Viannia) braziliensis Transmission
}

\author{
Gustavo Adolfo Sierra Romero ${ }^{+}$, Raimunda Nonata Ribeiro Sampaio, \\ Vanize de Oliveira Macêdo, Philip Davis Marsden
}

\author{
Núcleo de Medicina Tropical, Universidade de Brasília, Campus Universitário, Asa Norte, 70919-970, \\ Brasília, DF, Brasil
}

\begin{abstract}
Sixty eight patients with localized cutaneous leishmaniasis from an area with Leishmania (Viannia) braziliensis transmission had cultures performed with a modified Marzochi's vacuum aspiratory puncture technique to establish sensitivity and contamination rate with this new method. Overall sensitivity of three aspirates was $47.1 \%$; $\left(C_{95 \%} 39.4 ; 59.4\right)$ significantly greater than the sensitivity of a single one aspirate. Fungal contamination was observed in 6/204 (2.9\%) inoculated culture tubes. We recommend that this useful technique should be adopted as routine for primary isolation of $\mathrm{L}$. (V.) braziliensis from localized cutaneous ulcers.
\end{abstract}

Key words: Leishmania (Viannia) braziliensis - culture sensitivity - fungal contamination vacuum aspiratory technique

Culture sensitivity for diagnosis of cutaneous leishmaniasis caused by Leishmania (Viannia) braziliensis (L.V.b.) has shown variable results depending on quality of culture media (Shaw \& Lainson 1981, Cuba et al. 1986), collection technique (Evans 1989) and other characteristics such as disease duration and previous use of anti-leishmanial drugs (Cuba et al. 1984). Marzochi et al. (1993) described a new collection technique using direct inoculation of culture tubes containing NNN media with a liquid phase through a skin puncture system with five to ten mililiters vacuum.

We modified the culture medium using a smaller amount of an unenriched liquid phase composed of isotonic saline solution with gentamicin, resuming $15 \mathrm{ml}$ vacuum in each tube. We used the same aspiratory puncture system with commercial needles but the aspiration was modified by allowing air to come into the tubes when pulling the needle out to obtain a larger amount of inoculum. We studied the sensitivity of this method for diagnosis of cutaneous leishmaniasis in a group of pa-

\footnotetext{
This work was supported in part by the Fundação Nacional de Saúde, Ministério da Saúde, Brazil.

${ }^{+}$Corresponding author. Fax: +55-61-273.2811. E-mail: gromero@unb.br

deceased

Received 23 October 1998

Accepted 22 February 1999
}

tients with suspected leishmanial ulcers and a positive Montenegro's skin test in a rural area of the State of Bahia, Brazil where L.V.b. transmission is endemic (Llanos-Cuentas et al. 1984, Rosa et al. 1988).

\section{MATERIALS AND METHODS}

Culture medium was prepared using blood agar base no. 2 (DIFCO cod. 0696-17) with 15\% defibrinated rabbit blood which was added after fusion of agar at $50^{\circ} \mathrm{C}$. Gentamicin $(100 \mu \mathrm{g} / \mathrm{ml})$ and 5 -fluorocytosine $(100 \mu \mathrm{g} / \mathrm{ml})$ were added and the mixture was distributed in $10 \mathrm{ml}$ glass tubes (Vacutainer ${ }^{R}$ ). Tubes were covered with rubber caps and vacuum restored aspirating $15 \mathrm{ml}$ with a $20 \mathrm{ml}$ syringe using a 22 gauge needle. A liquid phase composed of $0.3 \mathrm{ml}$ isotonic saline with gentamicin $(100 \mu \mathrm{g} / \mathrm{ml})$ was added immediately before the aspiratory puncture by injection through the rubber cap with a $1 \mathrm{ml}$ syringe and a 22 gauge needle. All injection procedures were performed through the rubber cap after desinfecting it with $0.2 \%$ iodinated alcohol.

The aspiration puncture was made with the commercial Vacutainer ${ }^{\mathrm{R}}$ needle holder dispositive and 21 gauge needles for vacuum blood extraction. The puncture site was cleaned with $0.2 \%$ iodinated alcohol and local anesthesia was induced with $0.3 \mathrm{ml}$ lidocaine (2\%) injected with a $1 \mathrm{ml}$ syringe with a 13 gauge needle. The procedure was performed through intact skin close to the ulcer border at a $20^{\circ}$ angle with a rotatory movement 
and finally was pulled out allowing air come into the needle with the aspirated material. The material which adhered to the glass wall of the tube was washed toward the solid phase using the liquid phase. The procedure was repeated at the same place three times in three separate tubes which were labeled as first, second and third aspirates. When patient had more than one ulcer only one was aspirated, usually the one with the most recent onset.

Culture tubes were kept at $22-28^{\circ} \mathrm{C}$ and were observed every day using an inverted microscope for 28 days. When positive, new tubes were inoculated to obtain parasites for cryopreservation. Culture aspiration and observation of leishmanial growth were performed by one researcher, thus avoiding inter-observer variations. All isolates were characterized with monoclonal antibodies at Instituto Evandro Chagas, Belém, State of Pará, Brazil.

Eligible patients were those with less than six cutaneous ulcers with two to 20 weeks of evolution who had a positive Montenegro's skin test. Pregnant women, children under eight, patients with more than five lesions, history of previous cutaneous lesions with typical scars suggestive of old leishmaniasis, mucosal involvement or history of anti-leishmanial treatment were excluded. Lesion number for inclusion was chosen to be less than six to differentiate clearly the localized clinical syndrome from disseminated cutaneous leishmaniasis (Carvalho et al. 1994). Montenegro's skin test was performed with $0.1 \mathrm{ml} \mathrm{L}$. (Leishmania) amazonensis (MHOM/BR/86/BA 125) antigen $(250 \mu \mathrm{g} / \mathrm{ml})$. Reaction of $5 \mathrm{~mm}$ diameter or greater at $48-72 \mathrm{hr}$ after intradermic injection were recorded as positive.

All patients were treated in a basic health unit at Corte de Pedra district, Presidente Tancredo Neves municipality, State of Bahia, Brazil with conventional drugs recommended by the Ministry of Health. The study was part of a research project aproved by de Ethics Comitee of the University of Brasília.

Group comparisons were processed using Epi Info 6.04 software.

\section{RESULTS}

Sixty eight patients were eligible among 131 attended at the Corte de Pedra's unit from August to November 1996. All were agricultural workers living in the cocoa production area in the southeast region of Bahia. Table I shows the characteristics of the sample. Sixty six percent had one lesion, $16.2 \%$ two lesions, $13.2 \%$ three lesions and $4.4 \%$ more than three.

Cultures were positive in 32 patients $(47.1 \%$ $\left.\mathrm{CI}_{95 \%} 39.4 ; 59.4\right)$. The mean time to obtain a positive result (at least one culture tube) was 9.8 days
(2-26 days; $\mathrm{CI}_{95 \%}$ 8.8; 10.8). Eighty one percent of positive culture tubes were positive in the first two weeks of observation. Nineteen patients out of $32(59.3 \%)$ had a positive result in only one culture tube (four in the first aspirate, six in the second and nine in the third one). Eleven patients (34.3\%) had a positive culture in two tubes (five in the first and second aspirates and six in the second and third aspirates) and two patients had three positive aspirates (6.2\%). Results among different aspirates of the same patient had a poor concordance. The figure shows the dynamics of parasite growth during the 28 days observation time. The sensitivity was $14.7 \%, 27.9 \%$ and $26.5 \%$ for the first, second and third aspirates respectively. Fungal contamination was observed in cultures from five patients. There was contamination of one tube in four patients and two tubes in one. Contamination rate was $2.9 \%(6 / 204$ inoculated tubes). The mean time to develop contamination was 16 days (10-22 days; $\mathrm{SD}=5.2)$

There was no influence of age, sex, number of lesions, multiple lesions, presence of adenomegaly, painful lesions or the Montenegro's skin test diameter over the chance of a positive culture (Table II). Disease duration was slightly longer in pa-

\section{TABLE I}

Characteristics of 68 patients with localized cutaneous leishmaniasis

\begin{tabular}{lcc}
\hline Variable & \multicolumn{2}{c}{$\mathrm{N}=68^{a}$} \\
\hline Mean age (years) & 26.60 & $(4.61)$ \\
Sex (male) & 50 & $(73.5 \%)$ \\
Mean number of lesions & 1.57 & $(0.93)$ \\
Mean disease duration (weeks) & 5.35 & $(3.48)$ \\
Adenomegaly & 56 & $(82.4 \%)$ \\
\hline
\end{tabular}

$a$ : standard deviation for means and $\%$ for categorical variables.

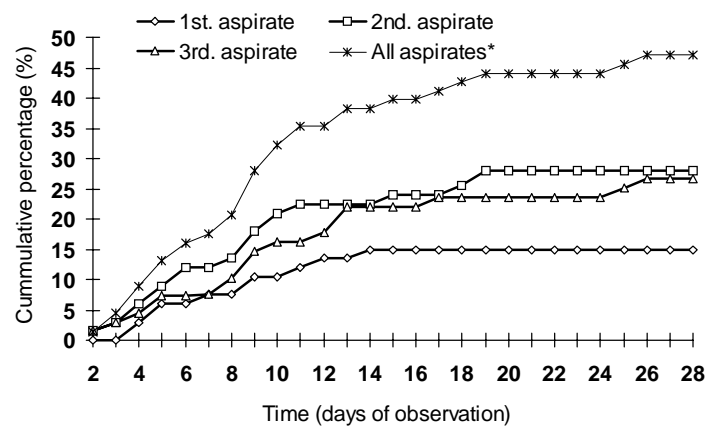

Cummulative percentage of positive cultures for the 1st, 2nd, and 3rd aspirates during the 28 days of observation. * All aspirates curve corresponds to cummulative percentage of patients with at least one positive result among the three aspirates. 
TABLE II

Influence of other variables on culture results of 68 patients with localized cutaneous leishmaniasis

\begin{tabular}{lccrc}
\hline Variable & $\begin{array}{c}\text { Positive culture } \\
\mathrm{N}=32^{a}\end{array}$ & $\begin{array}{c}\text { Negative culture } \\
\mathrm{N}=36^{a}\end{array}$ & $\begin{array}{c}\text { Statistical } \\
\text { test }\end{array}$ & P value \\
\hline Mean age (years) & $27.5(14.7)$ & $25.8(14.7)$ & $0.45^{b}$ & 0.64 \\
Male sex & $24(75)$ & $26(72)$ & $0.00^{c}$ & 0.98 \\
Median disease duration (weeks) & $4.0(3.0)$ & $4.0(5.0)$ & $501.5^{d}$ & 0.35 \\
Median number of lesions & $1.0(1.75)$ & $1.0(1.0)$ & $549.0^{d}$ & $0.03^{c}$ \\
Multiple lesions & $11(34)$ & $12(33)$ & $0.01^{c}$ & 0.86 \\
Adenomegaly & $26(81)$ & $30(83)$ & $0.04^{c}$ & 0.92 \\
Painful lesions & $18(56)$ & $20(55)$ & $-1.62^{b}$ & 0.85 \\
Mean Montenegro skin test & $16.6(6.4)$ & $19.5(8.1)$ & & 0.11 \\
diameter (mm) & & & &
\end{tabular}

$a$ : standard deviation for means, $\%$ for categorical variables and interquartile range for medians; $b$ : T test; $c: \chi^{2}$ test; d: Mann Withney U test.

tients with negative culture but the difference did not achieve statistical significance. All isolates were characterized as L.V.b. (data not shown). All patients had a confirmed parasitological diagnosis by at least one of the following methods: histopathological sections, hamster inoculation and imprint of skin biopsy material or lymph node aspiration (data not shown).

\section{DISCUSSION}

Reports of prospective studies to assure sensitivity of culture for the diagnosis of cutaneous leishmaniasis frequently involve patients with infections due to diverse species, disease acquired at different geographic regions and a wide variety of clinical forms (Weigle et al. 1987, Barral et al. 1987). Problems arise when these results are used to guide diagnostic interventions in areas with transmission of other species and different clinical presentation. This is the first study to define sensitivity of a modified original culture technique under field conditions in a significant sample of a prospectively evaluated population, describing the most important clinical characteristics of the cutaneous leishmanial disease. We established that the vacuum aspiratory technique is reasonably sensitive. Culture of three aspirates significantly improved sensitivity. The contamination rate in our study was very low (2.9\%) compared to $28.6 \%$ in the original proposal (Marzochi et al. 1993). The greater sensiivity could be explained by modifications of culture medium specially those of lowvolume liquid phase which was not enriched as previously recommended by Shaw and Lainson (1981). Cuba et al. (1984) showed that contamination with fungi was an important technical problem which affected $27.5 \%$ of cultures using the same culture medium. This observation indicates that the vacuum aspiration procedure could be crucial to diminish contamination rate.
We suggest that this modified vacuum aspiratory puncture technique could be adopted as routine for L.V.b. primary isolation from localized cutaneous ulcers.

\section{ACKNOWLEDGEMENTS}

To Dr Edna Ishikawa for identification of our stocks with monoclonal antibodies, Dr César Cuba Cuba for comments about culture modifications, Dr Roque Almeida for the Montenegro antigen preparation and Mr Tércio Pereira Rodrigues for technical assistance during the cryopreservation procedure.

\section{REFERENCES}

Barral A, Almeida RP, Jesus AR, Neto EM, Santos IA, Johnson Jr W 1987. The relevance of characterizing Leishmania from cutaneous lesions: a simple approach for isolation. Mem Inst Oswaldo Cruz 82: 579.

Carvalho EM, Barral A, Costa JML, Bittencourt A, Marsden P 1994. Clinical and immunopathological aspects of disseminated cutaneous leishmaniasis. Acta Trop 56: 315-325.

Cuba CC, Llanos-Cuentas EA, Barreto AC, Magalhães AV, Lago EL, Reed SG, Marsden PD 1984. Human mucocutaneous leishmaniasis in Três Braços, Bahia-Brazil. An area of Leishmania braziliensis braziliensis transmission. I. Laboratory diagnosis. Rev Soc Bras MedTrop 17: 161-167.

Cuba CAC, Netto EM, Marsden PD, Rosa AC, LlanosCuentas EA, Costa JML 1986. Cultivation of Leishmania braziliensis braziliensis from skin ulcers in man under field conditions. Trans $R$ Soc Trop Med Hyg 80: 456-457.

Evans D 1989. Handbook on Isolation Characterization and Cryopreservation of Leishmania, WHO, Geneva, 45 pp.

Llanos Cuentas EA, Marsden PD, Lago EL, Barreto AC, Cuba CC, Johnson WD1984. Human mucocutaneous leishmaniasis in Três Braços, Bahia-Brazil. An area of Leishmania braziliensis braziliensis transmission. II Cutaneous disease. Presentation and evolution. Rev Soc Bras Med Trop 17: 169-177. 
Marzochi MCA, Teixeira PC, Marzochi KBF, Conceição NF, Coutinho W, Brito DB 1993. Vacuum aspiratory puncture system for Leishmania culturing, isolation and transport, preliminary report. Rev Inst Med Trop São Paulo 35: 301-303.

Rosa AC, Cuba CC, Vexenat A, Barreto AC, Marsden PD 1988. Predominance of Leishmania braziliensis in the regions of Três Braços and Corte de Pedra, Bahia, Brazil. Trans $R$ Soc Trop Med Hyg 82:
409-410

Shaw JJ, Lainson R 1981. The in vitro cultivation of members of Leishmania braziliesis complex. Trans R Soc Trop Med Hyg 75: 127.

Weigle KA, Dávalos M, Heredia P, Molineros R, Saravia NG, D'Alessandro A 1987. Diagnosis of cutaneous and mucocutaneous leishmaniasis in Colombia: a comparison of seven methods. Am J Trop Med Hyg 36: 489-496. 